\title{
Critical Care Nurses Competency Level on the Administration of Microinfusion Medication at Critical Care Unit Kenyatta National Hospital
}

\author{
${ }^{1}$ Isaac Nyabuto Onwonga ${ }^{*}{ }^{2}$ Hannah Inyama, ${ }^{3}$ Eve Risper Rajula
}

Lecturer, University of Nairobi

\begin{abstract}
Background of the study: Most drugs given as Microinfusion require infusion pumps to administer. They are very potent with very narrow therapeutic index and any small changes on the process results in enormous effects to patients. The nursing profession has a duty to advocate for patients rights as well as do no harm. One of the core goals of nurses is medication administration; this puts nurses in the last line of defence against medication administration errors (MAEs). This study aimed to look into the roles played by nurse that hamper the efforts to reduce the Microinfusion MAEs on which minimal studies have been done.
\end{abstract}

Objective: This study determined the competency level influencing the administration of Microinfusion medication by critical care nurses at Kenyatta National Hospital's (KNH) Intensive Care Unit (ICU).

Significance of study: Local data in the area of Microinfusion MAEs is not available, specifically KNH's ICU. This study therefore sought to breech this gap and hopes to influence policy on management of critical patients, patient safety, environment, and curriculum development so as to reduce Microinfusion MAEs.

Methodology: This study used a descriptive cross-sectional study design, simple random sampling was used to pick 64 participants. Quantitative data was analyzed by both descriptive and inferential statistics, which included regression analysis. Descriptive statistics were presented by use of the mean, percentages and standard deviation. Chi-square was used to determine statistical significance of the differences in proportions and logistic regression was used to identify factors that lead to Medication administration errors. Necessary ethical approval was sought.

Results: The prevalence of MAEs was at $64.1 \%$ in the last six months, $65.6 \%$ of the respondents reported lack of supportive supervision, $37.5 \%$ of the respondents reported not to know mechanisms in place for reporting Microinfusion medication errors. This prevalence was of statistical significance when cross tabulated with critical care nurses competency level $(\mathrm{p}<0.05)$ on aspects such as; having prescription checks $[95 \% \mathrm{CI}=0.000-17.9 ; \mathrm{p}=0.008]$, working experience, type of medication error, checking weight of patients $[\mathrm{p}=0.019]$, reporting of the errors $[95 \% \mathrm{CI}=0.1-0.8 ; \mathrm{p}=0.019]$, documenting drug errors and monitoring patients after drug administration.

Conclusion and recommendation: The prevalence of Microinfusion administration errors in KNH-ICU is high. There is need to ensure that nurses are always equipped with adequate knowledge and experience in drug administration through trainings and mentorship programs as this will reduce medication errors and increase safety of patient in health facilities.

\section{Introduction}

In Critical care unit (CCU) patients change conditions suddenly and fast, it doesn't allow too much time to consult before making life saving interventions, therefore a critical care nurse is expected to be in the forefront in making critical decisions that can save the life of the patient before any further investigations and consultations for the next course of management happen. This requires that a lot of critical thinking is employed as well as existing knowledge on protocols and standard of operation in procedure manuals, 
produced by the practice governing body. The nurse should also be knowledgeable on drugs and modalities of administration used in emergency setups (Karavasiliadou and Athanasakis, 2014) all this puts additional pressure on the nurse as it takes time to master this art of care. Therefore knowledge of the various drugs administered in ICU as well as the standard operating procedures that guide the administration is crucial in managing the critically ill patients by critical care nurses and other healthcare providers.

During Microinfusion medication administration, critical care nurses act as the last line of defence against harm to the patient after all checks have been passed. They hold a superior role in saving patients from harm that could be as a result of medication administration error. It's therefore important to have systems and processes in place and equip the environment within which they work, and any necessary support systems to make it possible to achieve this roles that aim at protecting the health of patients (Faye et al., 2010). The systems and processes are all grouped as standards of care. These functions apply to each individual department, unit, or service within the organization as well as to the entire organization structure (Joint commission international accreditation, 2011), when all the systems work well together then the chances of Microinfusion medication administration errors are significantly reduced.

There are available studies on the processes of Microinfusion medication administration, an inside look at the process of Microinfusion medication administration, (Aljadhey et al., 2016) found out from his study that $10 \%$ of errors were because of lack of drug knowledge and $40 \%$ of errors were due to memory lapses, they were all cumulatively responsible at the administration stage. This high numbers on memory lapse were not surprising because health care workers work within an interrupt-driven environment hence slips and memory lapses are very common as they may have to deal with more than one communication task and most of the time simultaneously.

While it's expected that nurses with serving experience may prevent many errors since they have familiarity to the environment, drugs, dosages, and the population of patients in the unit, this nurses are leaving the workforce as they get older and more experienced. Hospitals are increasingly relying on new nurses with low level experience (Morrison et al., 1994) which may lead to an increase in cases of errors when administering medication, as it takes time for one person to gain the skills and the required knowledge on the administration of Microinfusion medication and the management of the undesired events that may result from a medication error.

This study aimed to assess the challenges in administration of Microinfusion medication by critical care nurses at KNH ICU based on the competency level. By focusing on the current standard operating procedures of practice that have been put in place, the protocols and processes that are involved in the nurses practice, we were able to identify challenges and gaps that exist in practice that lead to Microinfusion medication administration errors, the study also identified modalities laid in place to prevent such errors, and managing consequences.

\section{Critical care nurses competency}

This part looks at the knowledge level of the nurse and their skills and competencies required in performing specific factions in the care of critical patients in the ICU in comparison to what is expected of the nurse at their level of practice. It will as well look at the practice of nurses at different levels as reported by other studies. On that account, comparing the performance of the nurses with the knowledge level;

\subsection{Competence in high alert medication administration}

When it comes to Microinfusion medication administration, performing technical tasks of medication administration is very important but not the only important thing to do, it's also important to do ethically safe and competent medication management of medication administration which requires that the administrator of medication in which case most of the time is a nurse taking care of the critically ill patient must have a good judgment of his or her actions after review of the patient to have a clear picture. The nurse should also have the knowledge of the drugs to be administered including the adverse effects and how to manage these adverse effects and have experience and skills needed to carry out the processes without forgetting any process steps (Bassi, Park and Azevedo, 2013) Thus, the nurse working it CCU should pay keen attention to details which in some case would look insignificant but very crucial in the management of patients receiving Microinfusion medication in the ICU setup. 
To be able to manage a Safe and effective medication practice efforts have to be made to achieve the results and this has to do with many individuals and reliable systems. When nurses are skilled and have knowledge of the right orders they are at liberty to question medication orders that are unclear or inconsistent with therapeutic needs of the client and client outcomes or best practice (College and Association of Registered Nurses of Alberta, 2014) that being the case, the nurse has to have the right knowledge and competency in practice through many sources to enable them to advocate for better management of medication to ensure patient safety, this can only be possible through a lot of research and specific case reports as it reported experiences of other health workers and the outcomes, this empowers the nurse to engage in constructive dialogue with other care givers in making decisions of management.

In patients admitted in ICU, to restore and maintain the cardiac output and perfusion pressure is the major concern of hemodynamic therapy. A study conducted in a 15-bed university hospital adult medical ICU during a routine rounds in civils de lyon in france demonstrated that, vasopressors, inotropes, or both are required for the Patients who do not respond to initial fluid resuscitation. Since they are potent, have a very short half-life and a narrow therapeutic index. Any slight variations could induce life-threatening challenges and cause variations in arterial pressure as well as cause variations in cardiac rhythm. Therefore, these drugs require atomization of the smart pumps to deliver the required doses as well as maintain the desired doses to enable the drugs to give the desires therapy outcomes (Cour et al., 2013) as a result, smart pumps reduce the chances of having to engage in active resuscitation all the time as a result of delivery of wrong doses to the patients as well as it reduces the chances of under treatment.

Even though most studies could not show that there is no clear cut between MAEs and their contributing factors, most studies have not shown a strong cause and effect relationship, the whole system needs to be looked at including trainings conducted to the staff, staffing ratios, number of activities carried out by one nurse in one shift to a patient in the unit and destructions from the nature of environment. The critical care nurses pointed to this as some of the main reasons why the errors continue to exist and contribute to nurses not meeting the demands of the patient they are looking after. These findings are similar with the findings from a study done by the world health organization trough their independent reports (WHO, 2017) that being the case, most ICU settings should have comprehensively looked at to ensure that they meet the standards to enable nurses perform according to the known best practices.

For the nurse to have it easy to manage Microinfusion medication and reduce the errors associated with medication administration, there must be a clear communication all the way from the time of ordering of Microinfusion medication is made to the time of ordering from the supplying department to the time the order is actually delivered to the patient so there is need to have clear orders from the prescriber and they should entail all the following but not limited to: the full names of the patient, the prescription dates, use generic names of the drugs and avoid trade names to have common names used for prescription, give clear drug strength where applicable and dosing, clearly indicate route, frequency, duration these drugs have to be administered. The prescriber should have his/ her name well written so that if clarity has to be sought one does not struggle finding out who the prescriber could be, the order has to be signed and if possible indicate the purpose for the order or prescription and monitoring as required. Most of the time there is no common or shared understanding of the use of abbreviations in the medication process. Abbreviations lead to confusion and misinterpretations of prescription, most of the time they can be confused for something else which can result in very serious and often fetal errors in Microinfusion medication.(College and Association of Registered Nurses of Alberta, 2014) on that account, all the care givers working or caring for patients in an ICU settings should at all times endeavor to build on a good communication process, as well they should be patient with each other so that they can hear and understand each other's point of view or even suggestions that could be beneficial but overlooked because they were not clearly communicated or because one was not given a chance to give their views. The nurse being the primary person taking care of the patient comprehensively should be able to give critical information about the patient that will be able to help in the care of patients.

To avoid any forms of confusion when administering Microinfusion medication one has to perform necessary checks, so as to avoid errors that would become very common when managing patients if this checks are not looked into. According to six rights of medication administration studied by (Edwards and 
Axe, 2015), the following principles can improve safety of Microinfusion medication if followed properly. They include but not limited to: identifying the right patient, selecting the right medication, calculating the right dose, identifying the right route, administering the medication at the right time, and using the right documentation (Edwards and Axe, 2015) If followed strictly, Microinfusion medication administration errors will be prevented thus reducing the cost burden on the patient and by extension the morbidity and mortality in critical care patients (Ebrahimipour et al., 2014) That being the case, all this will require trained and competent nursing professional to be achieved.

After WHO encouraged reporting of errors in the year 2004 where they encouraged looking at the problem from all angles rather than just blames and victimization, many studies have been done to find out the progress of these reports, An observational study done and published by the WHO (World Health Organisation (WHO), 2008) entitled rebuilding trust in the health care team revealed that most of the time it's very tempting to apportion blame and victimize individual practice or just one issue or person involved in an incidence. But that could prove too simple and an exercise in futility. It's out rightly not right for one individual person to be blamed without carefully looking at the whole system and taking a good analysis to finding out clearly where the problem lies and what could have contributed to the wrong practice or even where exactly the loophole within the system is. There is need in strengthening the defence that generally exists in the health-care system as a whole. All this should be done without necessarily pointing out fingers to individual health-care workers. That does not imply that individuals are not accountable for their roles (World Health Organisation (WHO), 2008) However, relying on blame approach only will most likely burry problems under and make it impossible to carry a honest and effective strategy that can lead to patient safety

In the prospective observational study carried out in the University Hospital (Girardis et al., 2009) reports that when patients with a diagnosis of shock were admitted in the ICU and were started on Microinfusion medication in a single-centre experience. The study demonstrated that it was important to address specific programs which were addressing the departmental problems in turn that existed and when these are replicated in all departments within the hospital setup then the whole hospital improves on evidence-based service provision to its clients. These practices enable improvement of the survival rates of patients receiving Microinfusion medication admitted in ICU.

Management of infusion pumps has to be done while all the teams are involved, the training of personnel should not just focus on a specific carder or specialty but everyone working in the ICU and may have a chance to be involved in the handling of the pumps, this makes it easy for the nurse as he or she doesn't end up being involved in doing everything. In their model of study (Girardis et al., 2009) focused on a multidisciplinary approach where each specific team play a key role in giving early and appropriate management to patients with automated pumps delivering high potent drug in the in-patient management program, these included educating health-care personnel and improving on the process to improve the adherence to guidelines and improving patient care optimization (Girardis et al., 2009), a multi disciplinary approach has been seen to give a better outlook and enable smooth running of care on the patients as no one does not feel helpless because they were left out of the training or the management of the infusion pumps when delivering Microinfusion medication to the patient.

\subsection{Competence in administration by use of technology and medication calculations}

One of the most valued nurse's professional responsibility is the administration of medication and therefore there is need to ensure that proper training on drug management is prioritized so that to increase patient safety (World Health Organization, 2014). A study conducted in the Middle East by (Alsulami et al., 2015) with the focus on nurses working in the pediatric units revealed that most nurses were not adhering to the policies that had been put in place to improve performance and bring about uniformity of practice, the study also noted that it was urgent to review the guidelines, procedures and frameworks of Microinfusion medication administration from time to time to ensure improved services and make them applicable for the changing times in practice. There was also need for continued training of nurses on the new treatment regimen, calculation of dosages and administration protocols of Microinfusion medication administration as this helps to shape the skills and mastery of the process. (Alsulami et al., 2015) hence, when a nurse is better informed and skilled it reduces the stress one has to undergo in the management of the patients, compared to when everything a nurse does when they are not trained which involve a nurse not being sure of the process 
or what is expected of them, they are not sure if what they did was what they were intended to do, taking note that most infusion pumps come with guidelines from the manufacturers.

Weight is used as a key measure for calculation of dosages for most Microinfusion medication for patients admitted in the ICU. Mathematical calculations and formulas are used to get required doses to the patients and its noted that this is not the case in most ICUs where you will find out that the calculations are frequently based on estimated weights especially in establishments where there are no ICU beds that can weigh the patients hence, increasing the risk of error (Moyen, Camiré and Stelfox, 2008) As the United Kingdom's Nursing and Midwifery Council states that medication administration requires scientific judgment, knowledge and skills application. On average $40 \%$ of the working time of any nurse in each shift deals with themes related to medications administration. Therefore, to improve the better management of Microinfusion medication the nurses who are left to do the calculations and then administer this medication have to get support on standardization of formulas so that they do not end up delivering medication regimen not intended, as well as during medication calculations the institutions should improve to alleviate chances where patients have to be given medication based on estimates of weight used to give estimated dosages.

Institutions should endeavour to keep their nurses working in the ICU informed and updated all the time, the department of patient safety should have a champion in every department in the hospital and more so in the ICUs where most errors are likely so that they can champion patient safety by ensuring standardization of formulas as well involve all the nurses in refresher training on medication management from time to time. At a steady state the rate of drug elimination is equal to the rate of maintenance of drug administration; the dosage used in maintenance which is a function of clearance is not used in the calculation of the maintenance dose of the drug dosing rate. The drug dose is calculated using a unit time.(Katzung and Trevor, 2015) If a nurse gets the formula wrong or somewhere within his or her calculations ends up with a wrong figure then the result will definitely be wrong which will lead to the patient receiving the wrong dosage, this can lead to harm of the patient.

It will be unfair to blame one party in all this because it may not be an individual problem but on the other hand nurses are advised not to carry procedures alone more so when they are not very sure of how they ought to be carried out (Morrison et al., 1994) thus the nurses should work hard to be informed of the current treatment guidelines, this can be made possible by creating personal time to read and if this is not possible the nurses working in the ICU department must keep informing each other and discussing conditions that are admitted in the wards to help the nurses handling the patients to understand what is expected of them and this gives the general understanding to the other nurses of all the patients, this on the other hand allows nurses to engage in constructive discussion when consulting each other as well as when they are seeking clarification. Partner nurses can as well remind their colleagues when they are witnessing a possibility of an error being carried out; this in turn will improve patient care and reduce the risks.

When administering Microinfusion medication which are high risk medications most of the time infused using pumps in a critical care setup, at KNH's ICU the nursing staff ensure that the infusion rate and dose programmed (which most of the time is calculated and fed into the infusion pump) are correct for the patient. According to (Erdman et al., 2017) The pump setting should be independently checked when high risk drugs are administered. Having two trained and licensed nurses independently check and recheck the infusion pump to ensure that the settings and the calculations have been well undertaken for high risk medications is a way to notice the errors in advance and avoid them.

Studies conducted in a Japanese hospital assessing working conditions of nurses which influenced near miss medical errors of Microinfusion medication administration. The nurses blamed the work load allocated to one nurse working within a critical care unit in relation to the experience of the nurse. Also when nurses are faced with experiences in practice which can either be through studies or continuous medical trainings planned and carried out within the facility which at the end of the day encourage knowledge and improve practice that can in turn help nurses to be able to detect and prevent Microinfusion administration errors before they occur. Therefore newly employed nurses (recently graduated or change working environment) are more likely to miss or even may not detect signs of medical errors and even if they did it will be with difficulty and not be able to know how go about them as well as report them with the fear of victimization, this may also take time during the process of Microinfusion medication administration procedures.(Al-shara, 
2011) then, the approach should focus more on patient safety not entirely just on the nurse who made an error, to reduce the errors then the nurse has to undergo a vigorous induction process before they start handling patients and should be under supervision of a more skilled nurse and who has a passion to help others become better in practice. So that if the nurse is comfortable with his or her practice then it becomes easy to detect errors as well as they will feel at easy to report the errors.

There are high incidents of Microinfusion medication administration errors, institutions with good error reporting policies have better mechanisms by which medication administration errors are reported and proper channels that allow for speedy resolution that cater for patient safety. A study conducted in Ethiopia on factors contributing to Microinfusion medication administration errors by (Sada, Melkie and Shibeshi, 2015) revealed that $71 \%$ of those who responded to the study admitted that in the last 12 months of their practice they had made medication administration error. There was a very low percentage of about $0.7 \%$ of the cases of dose administration considered to have met the criteria for medication administration. Therefore, presenting a very high figure in the findings which made observations that an Ethiopian hospital had displayed protocols, a majority number of the nurses did not follow those protocols for uniformity of medication administration (Abdel-Latif, 2016). Majority of the errors have been attributed to an illegible handwritings, distraction during drug administration, a low nurse to patient ratio, poor communications, lack of proper staffing, lack of continuous nurse education and training leading to incompetent nursing team that is not updated on the current managements of conditions and low skills to a practice (McDowell, Ferner and Ferner, 2009) as a result, this increases the time one takes to handle or accomplish activities putting up an increased work load to the nurse and as a result poor management of the patient.

In a prospective observational study conducted in 102 severely injured patients, it was observed that infusion of crystalloid solution during the first 24 hours was associated with increased pulmonary dysfunction. Although no direct relationship between fluids loading and pulmonary dysfunction could be established, but a new thought process was evoked for the indication of the use of Microinfusion medication during early stages of resuscitation. Moreover, restrictive fluid therapy and Microinfusion therapy to optimize the Mean arterial pressure (MAP) and the cerebral perfusion pressure (CPP) may also have beneficial effects in headinjured patients. Volume sparing effect of vasopressors may lead to decreased cerebral oedema and maintenance of adequate blood pressure in polytrauma patients with head injury, in whom even a single episode of low blood pressure may prove detrimental and worsen the outcome (Gupta, Garg and Ramachandran, 2017) on that account, the use of Microinfusion therapy if administered according to the available standard would result in beneficial results to the patients as well as reduce chances of resuscitation.

Each critical care Nurses are personally accountable for their practice and cases of wrong dose calculations and inadequate knowledge on Microinfusion medications administration; this may lead to medical legal issues for the nurse responsible for not upholding practice. Nurses play a major role in patients right advocating and have a duty to ensure no harm to patients, it is important to note their importance in improving patient safety via quality trainings on Microinfusion medications since any error may lead to increased cost through the stay of patients and lead to harm to the life of these patients. (Machado et al., 2018) Patient safety improves when systems effectively assure and improve patient safety.(Whalen, Finkel and Panavelil, 2015)(Li et al., 2015) that being so, the systems have to be put right to avoid the cases where errors are due to the systems not functioning or are not clear on what needs to be done when this or that happens.

In a study conducted in hospitals in Brazil on how nurses are affected cognitively when working in ICU, looking on the inventory that was used in the study $61 \%$ of the nurses in the study presented with psychological symptoms of stress. $45 \%$ of the $61 \%$ nurses that had shown stress had a gross score higher in one symptom accounting for symptoms of depression and anxiety. The study revealed that during a 24 hour shift in a CCU where there is increased workload as the day progresses leading to increased stress levels, decreasing attention span and attention process and a decline of psychomotor aspects (Machado et al., 2018) to reduce the stress levels which if left to accumulate for a long time may lead to depression, there has to be cooperation to have every part of subjects involved in the function of a working ICU play its part to ensure smooth running of services.

\subsection{Use of infusion pumps}


Infusion pumps have proved essential and contributed to improvements in patient care and safety, following the current inventions allowing for greater levels of control, accuracy and precision in Microinfusion medication delivery. The development of medical device technology combined with advanced medication and better requirements to control infusion therapy have increased the use of infusion pumps. Today infusion pumps that also include syringe pumps have been used in various clinical applications that have involved both life-sustaining as well as life-saving treatments within clinical areas like anaesthesia, intensive care and oncology where patients most of the time are on Microinfusion medication.

\subsection{Challenges in the use of infusion pumps}

There have been so many challenges in the use of infusion pumps most of which have been captured in studies that have been conducted over a period of time to enable the manufacturers improve the quality of these pumps to give optimal output and reduce chances of errors. A report of medical products agency of august 2014, a competent authority that is responsible for the surveillance of medication equipment in the Swedish market noted that there were safety issues with infusion pumps. They sort to identify the problems and risks that users had observed and experienced using infusion pumps during a period between January 2011 and December 2012. They report that it was the highest number of incidents reported approximately 1700 cases, and that some incidents were so severe to the point that patient safety was not guaranteed (Medical Product Agency, 2014) hence the need for continued internal time to time checks by the patient safety departments in the hospitals to ensure that the infusion pumps are tested from time to time to ensure that faulty machines are detected as soon as possible, there also has to be a well supported biomedical department at every ICU hospital that responds $t$ o the needs of the unit in time and which will do surveys from time to time to ensure that the pumps are in good condition for use on patients to guarantee patient safety.

The report noted three major areas where they had noted problems: there were software related problems with infusion in some instances; the health care providers using the infusion pump had difficulties in knowing how, where and when to report incidences to the competent authority; and there were low rates of reported incidents compared to the ones observed, since individuals often had to postpone or refrain from reporting to the authority (Medical Product Agency, 2014)where the nurses feel inadequate in training on the use of infusion pumps and there is fear of taking responsibility for an error exist, it becomes so hard for the staff to do self-reporting of errors committed when no one is watching, when the environment provided gives the nurses the understanding that the effects are on patient safety and the nurse should work to ensure the patient is safe and that should not be shameful to do, then self-reporting becomes easy where there are proper channels in place.

The medical products agency in their recommendations(Medical Product Agency, 2014) noted that there should be established additional requirements for infusion pump manufacturers and users so as to improve knowledge and understanding of the use of infusion pumps, as well as to proactively improve the device to become user friendly by also increasing user awareness and management of infusion pumps by offering adequate and effective trainings to primary users who in this case happen to be nurses in the facilities. (U.S. Food and Drug Administration, 2010) therefore, much emphasis should be taken to ensure that the manufacture is involved in the training of the staff in the use of the pumps and ensure that they have an easy interface that is easy to use by the end user, the nurses should also be willing and ready to enhance technology in a positive way to impact on patient safety and making work easy.

A study in the Alberta health care services on patient safety improvement when using infusion pumps noted that for effective management of risks, the software used should be applicable and easy to use, the managers and staff that come into contact with infusion pumps should be educated and put on continuous support, the pumps must undergo regular maintenance and repair and that nurses should be able to troubleshoot. They also recommended that there should be procedure manuals available regarding the use of the pumps. The nurses should be able to do independent double checks when infusing medication, adverse events should be recorded and reported promptly (College and Association of Registered Nurses of Alberta, 2014) this should be done in order to ensure patient safety.

It's through the reports given by the end users that the manufacturers depend on to improve on the experience of the users, so nurses should be in the front line to make suggestion targeting to improve the end 
user's experience. An article by(Neil, 2017) on infusion pumps-markers looking to improve safety through interoperability reports that US FDA (United Stated Food Drugs Authority) between 2005-2009 received 56,000 reports on adverse infusion pump events, which were more than any other medical technologically in use, it reported that this events resulted in 710 patients deaths, during the time 87 pumps were recalled, from the institute of medicine reported that infusion pump users alone cost the health system $\$ 2$ bn annually . Nurses complained that infusion pumps been too complicated with interfaces that are not intuitive or easy to use which leads to errors noted that nurses wanted pumps that are simple to use, reliable and safe to patient.

\subsection{Selecting a syringe pump to use for infusion}

In a report by WHO on frequently asked questions on infusion pumps states that in order to select a safe syringe pumps should be reliable and electrically safe, able to deliver infusion accurately and consistently easy to set up and use , able to lock instructions, should be portable and robust, powered with both batteries and mains, should be usable with syringes of all sizes, should be equipped with and override rapid infusion facility, should be capable to alert when there is occlusion or time to change syringe and also able to display the rate of infusion and volume infused (World Health Organisation (WHO), 2012) as a result, make it a user friendly so that the nurse who handles it doesn't take too much time to figure out what should be done but have it easy to carry operations without problem.

\section{Results}

\subsection{Demographic Characteristics of the Respondent}

The researcher sought to find out the demographic characteristics of the respondents.

Majority of the respondents that is $59.4 \%(\mathrm{n}=38)$ were female while the male respondents were $40.6 \%$ $(\mathrm{n}=26)$ Shown on figure 2.

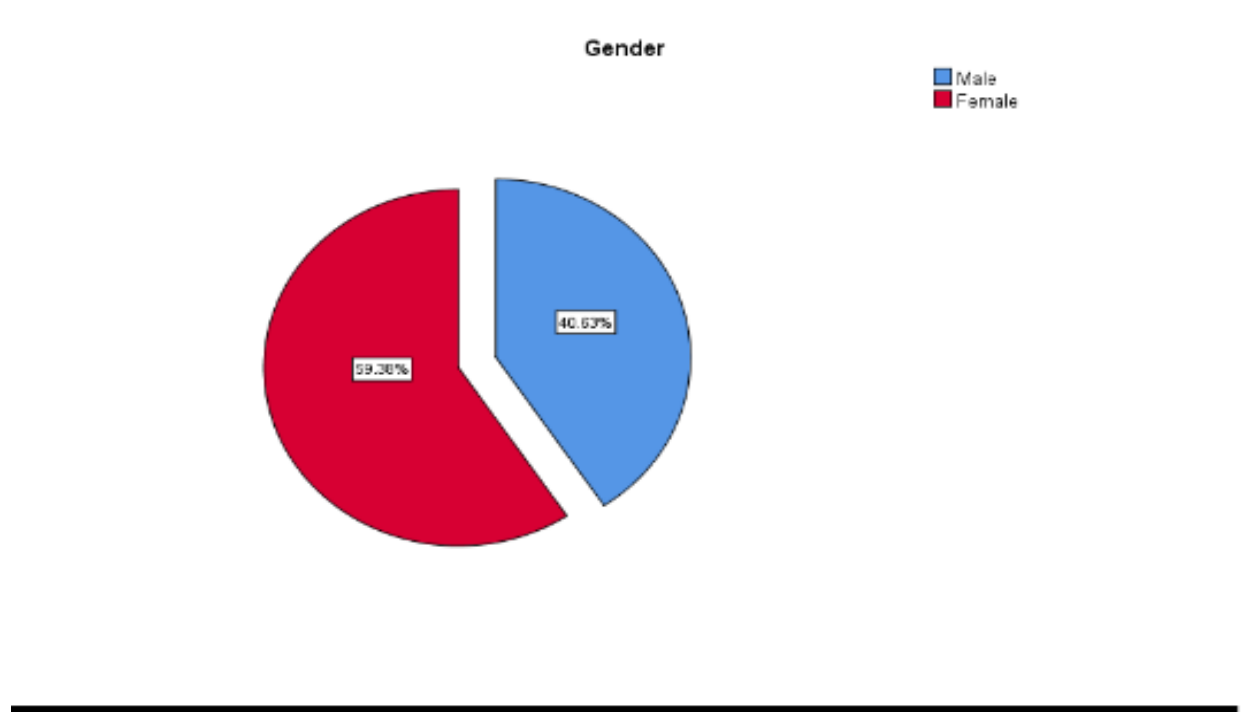

Figure 1: Pie chart of gender of the respondents

Amongst male respondents, $65.4 \%(\mathrm{n}=17)$ reported to have made Microinfusion medication administration errors within the last six months as compared to $34.6 \%(n=9)$ who did not report any error in the past six months.

The youngest respondent in terms of age was 31 years old while the oldest was 59 years. Mean 42, median 40 , standard deviation 6.8 , range 28 as shown in figure 3. 


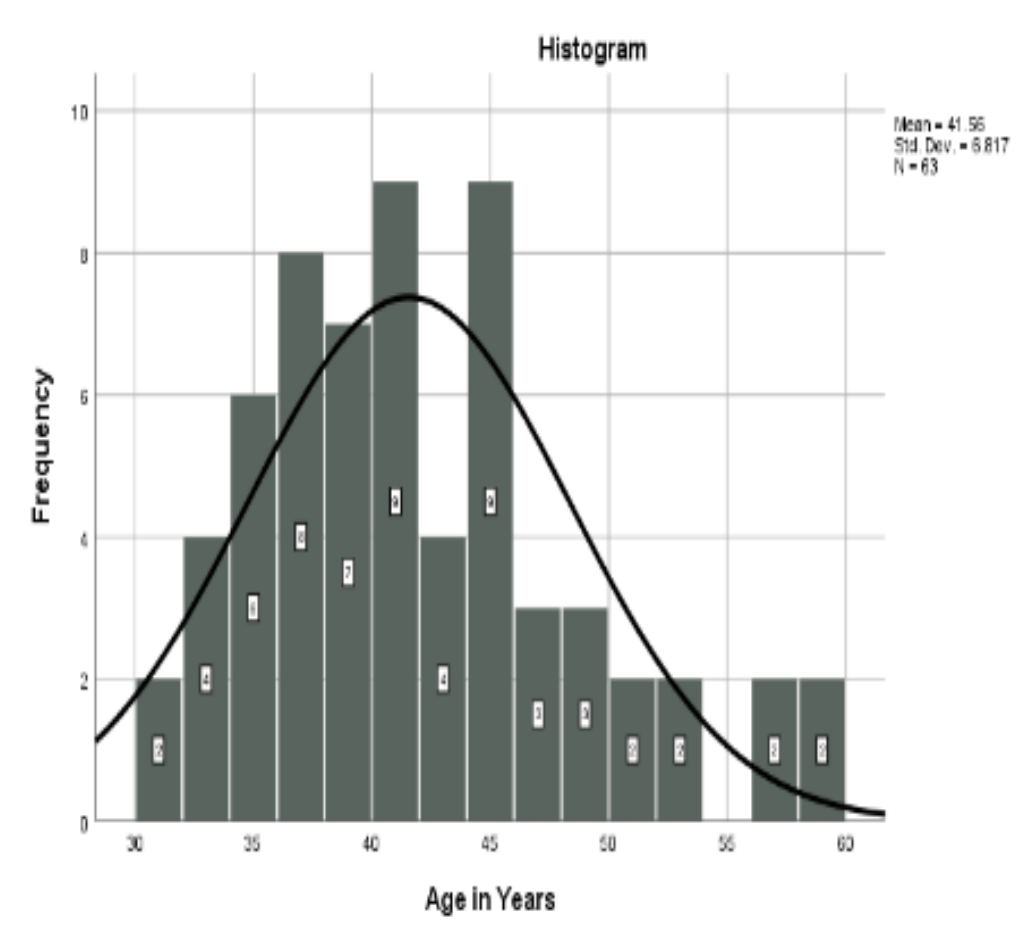

Figure 2: Histogram of the ages of the respondents

The researcher found out that on years of experience the respondent who had a least number of years of experience had 3 years while the one who had the highest had 36 years. Higher diploma $65.6 \%(n=42)$, Bachelor's degree in nursing 31.3\%(n=20), Master's degree and above 3.1\%(n=2) as shown in figure 4

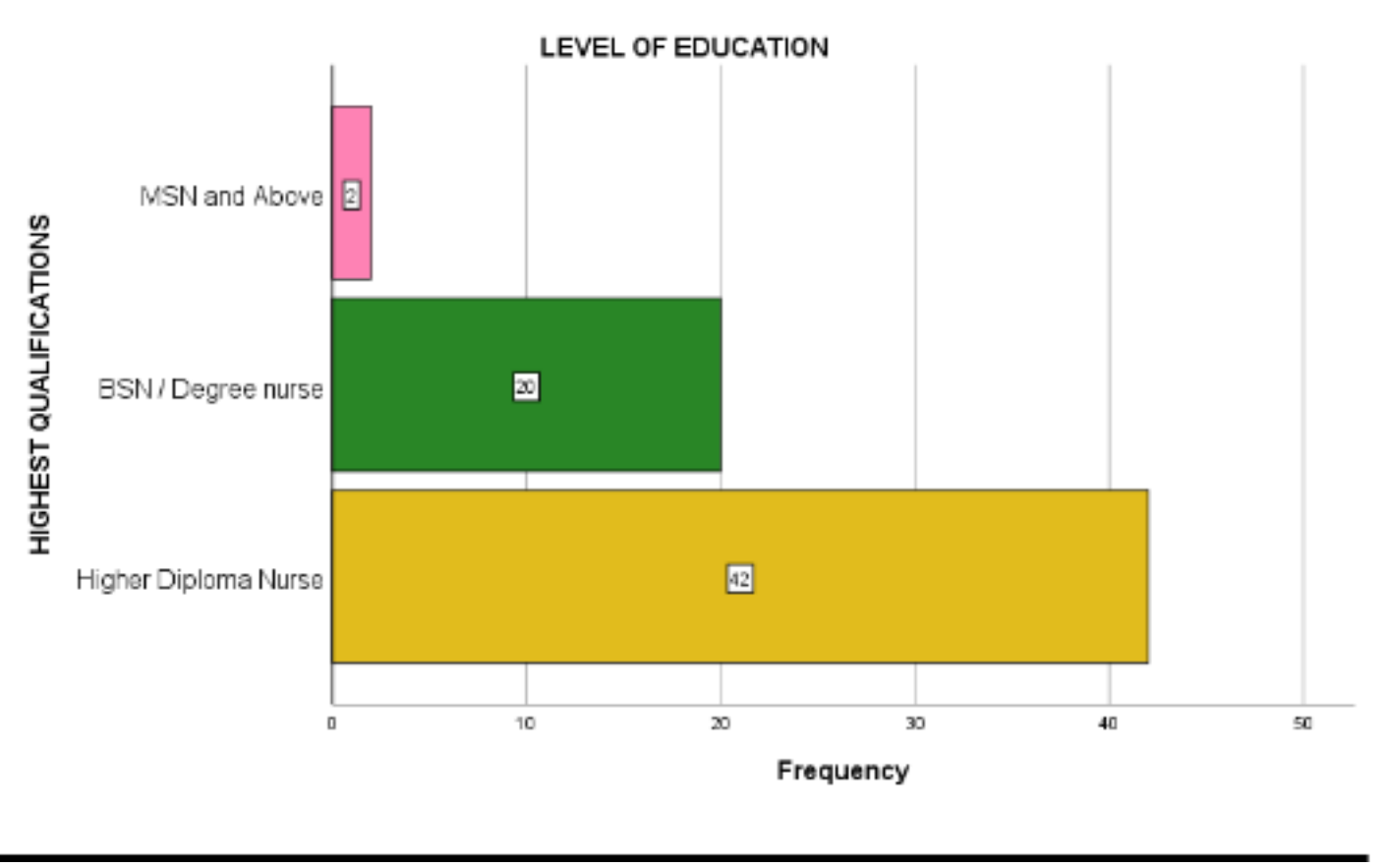




\section{Figure 3: Bar graph on level of education}

The researcher found out that among those who had Higher diploma $66.7 \%(\mathrm{n}=28)$ had reported Microinfusion medication administration errors in the last six months as compared to those who had a Bachelors degree in nursing and a masters in nursing.

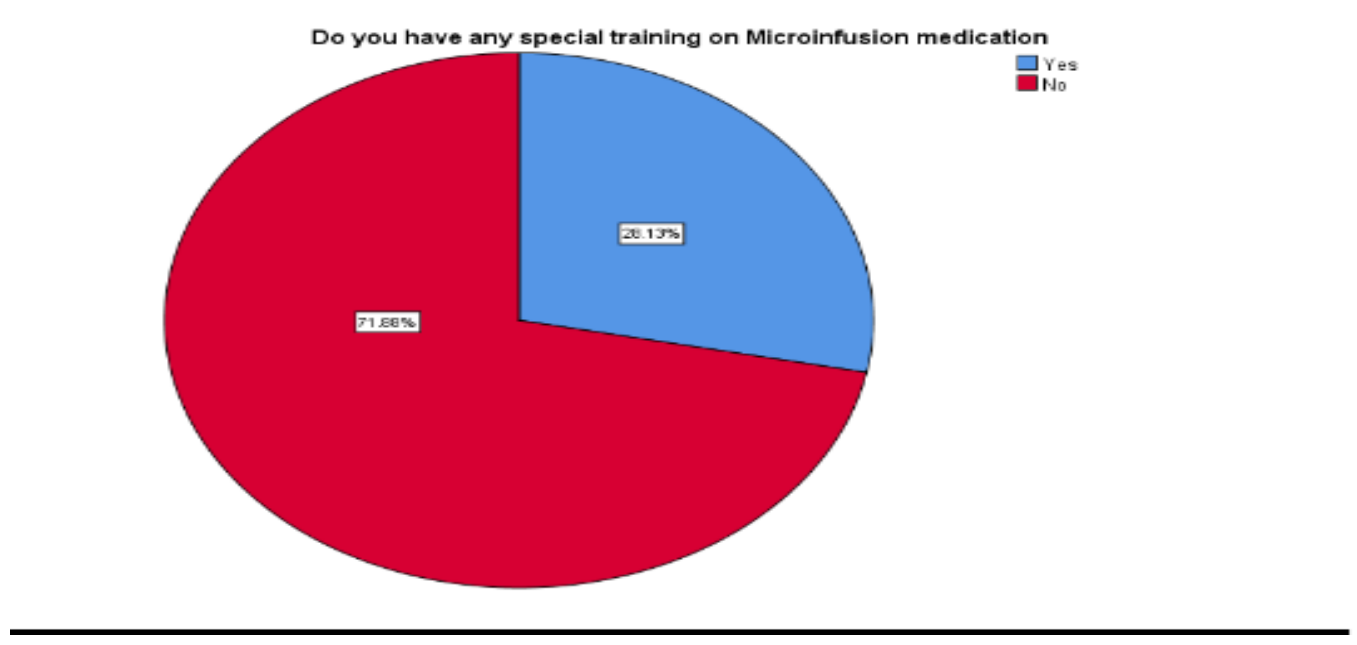

Figure 4: Pie chart on special training on Microinfusion medication administration

As shown in figure 5 above the participants who had special training were $28.1 \%(\mathrm{n}=18)$ while $71.9 \%$ $(\mathrm{n}=46)$ had no special training.

The study also found out that amongst those who had special trainings $66.7 \%(\mathrm{n}=12)$ reported Microinfusion medication administration errors in the last six months, while amongst those who had no special training on Microinfusion medication administration it was $63 \%(n=29)$.

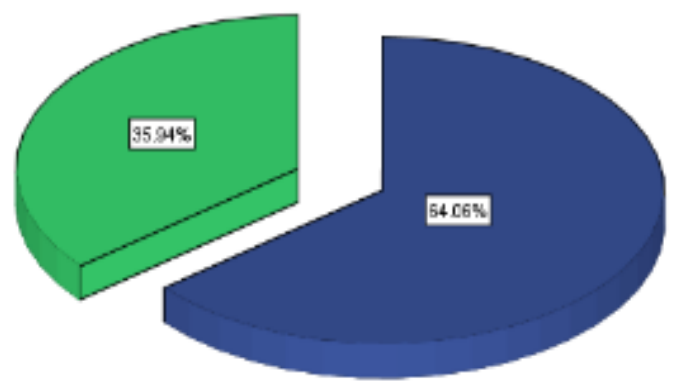


Figure 5: Pie chart on prevalence of medication administration errors (MAEs)

As shown above the researcher found out that in the last six months the respondents reported to have had $64.1 \%(n=41)$ MAEs while $35.9 \%(n=23)$ had no MAEs

The researcher found out that going by each respondent the one who reported the highest number of Microinfusion administration errors in 6 months among the ones that were asked had 8 incidences while the least had one incidence.

\section{Table 1: Number of reported Mae's incidences in the last 6 months}

\begin{tabular}{|l|l|l|}
\hline \multirow{2}{*}{ Mean } & Reported MAEs & 44 \\
\cline { 2 - 3 } & Never reported MAEs & 20 \\
\hline Median & 2.9773 \\
\hline Mode & 2.0000 \\
\hline Std. Deviation & 2.00 \\
\hline Minimum & 1.79778 \\
\hline Maximum & 1.00 \\
\hline
\end{tabular}

Among the types of Microinfusion medication administration errors the researcher sought to find out those respondents had made in the last 6 months type seven70.9\%( $n=11)$ were common among the respondents. On the type(s) of MAEs that were reported during the review period, this study established that majority of the respondents reported more than one type of error in a 6 month period.

Table 2: Relationship between demography and prevalence of micro infusion medication error in the last 6 months

\begin{tabular}{|c|c|c|c|c|}
\hline \multirow[t]{2}{*}{ Characteristic } & \multirow{2}{*}{$\begin{array}{l}\begin{array}{l}\text { Overall } \\
(\mathbf{n}=64)\end{array} \\
\%(\mathrm{n})\end{array}$} & \multicolumn{2}{|c|}{$\begin{array}{l}\text { Having made a medication } \\
\text { error in the last } 6 \text { months }\end{array}$} & \multirow[t]{2}{*}{ P-Value } \\
\hline & & Yes & No & \\
\hline \multirow{2}{*}{$\begin{array}{l}\text { Gender Male } \\
\text { Female }\end{array}$} & $40.6 \%(n=26)$ & $65.4 \%(n=17)$ & $34.6 \%(n=9)$ & 0.324 \\
\hline & $59.4 \%(n=38)$ & $61.5 \%(n=24)$ & $38.5 \%(n=14)$ & \\
\hline \multirow{4}{*}{$\begin{array}{l}\text { Highest qualifications } \\
\text { Higher Diploma } \\
\text { BSN / Degree nurse } \\
\text { MSN and Above }\end{array}$} & & & & \\
\hline & $65.6 \%(n=44)$ & $66.7 \%(n=28)$ & $33.3 \%(n=14)$ & 0.375 \\
\hline & $31.3 \%(n=20)$ & $55 \%(n=11)$ & $45 \%(n=9)$ & \\
\hline & $3.1 \%(n=2)$ & $100 \%(n=2)$ & 0 & \\
\hline \multirow{2}{*}{$\begin{array}{l}\text { Special training on Microinfusion } \\
\text { medication Yes } \\
\text { No }\end{array}$} & $28.1 \%(n=18)$ & $66.7 \%(n=12)$ & $33.3 \%(n=6)$ & 0.786 \\
\hline & $71.9 \%(n=46)$ & $63 \%(n=29)$ & $37 \%(n=17)$ & \\
\hline $\begin{array}{cr}\text { Ever made } & \text { medication } \\
\text { administration errors } & \text { (MAEs) in } \\
\text { the last } 6 \text { months } & \text { Yes } \\
\text { No } & \end{array}$ & $\begin{array}{l}64.1 \%(n=41) \\
35.9 \%(n=23)\end{array}$ & & & \\
\hline
\end{tabular}


The study revealed that there was no statistical significant between the demographic data and the incidences of Microinfusion medication administration errors at a $\mathrm{P}<0.05$ with no significant chi square values. Therefore, the researcher accepted the null hypothesis (H0) and rejected the alternative (H1) hence, showing that there was another source of Microinfusion administration errors other that Demographic Characteristics as shown in table 2.

\subsection{Critical nurse competency in use of infusion pump to administration medication and micro infusion medication administration errors in the last 6 months}

Respondents who reported making prescription checks always were $29.7 \%(n=19)$ while those who were not always making the checks $28.1 \%(\mathrm{n}=18)$, those who reported making prescription checks often were $17.2 \%$ $(\mathrm{n}=11)$. Among those who reported not having made prescription checks they had a high number of errors at $88.9 \%(\mathrm{n}=16)$.

On calculations of medication, those who were doing the calculations individually were $56.2 \%(n=36)$ those who cross checked the calculations with another nurse $43.7 \%(n=28)$. Most of the respondents said that they were taking part in preparing the infusions $76.6 \%(n=49)$ as compared with $23.5 \%(n=15)$. Amongst those who were not preparing the infusion medications $22 \%(\mathrm{n}=9)$ reported Microinfusion medication administration errors in the last six months.

Those respondents who were checking medication with the second registered nurse before administration were $15.6 \%(n=10)$ compared to those who confirmed $84.4 \%(n=54)$. None of the respondents said that he/she always checks with the second registered nurse before administration of infusion medications. Amongst those who were not making the checks with the second registered nurse before administration 87.8\% ( $\mathrm{n}=36)$ reported Microinfusion medication administration errors in the last six months compared with $12.2 \%(n=5)$ who said that they were checking quite often with the second registered nurse before administration medications.

Most of the respondents said that they were monitoring medication infusions $71.9 \%$ ( $=46$ ) unlike $28.1 \%$ $(\mathrm{n}=18)$ who said that they were not monitoring.

Table 3: Critical nurse competency in planning the use of infusion pump to administration medication

\begin{tabular}{|c|c|c|c|c|c|c|c|}
\hline \multirow[t]{2}{*}{ Characteristic } & \multicolumn{2}{|c|}{$\begin{array}{l}\text { Having made a } \\
\text { medication error in } \\
\text { the last } 6 \text { months }\end{array}$} & \multirow[t]{2}{*}{ OR } & \multicolumn{2}{|c|}{$95 \% \mathrm{CI}$} & \multirow[t]{2}{*}{$\begin{array}{l}X 2 \\
\text { value } \\
\text { (df) }\end{array}$} & \multirow[t]{2}{*}{$\begin{array}{l}\text { P- } \\
\text { Value }\end{array}$} \\
\hline & Yes & No & & $\begin{array}{l}\text { Lower } \\
\text { limit }\end{array}$ & $\begin{array}{l}\text { Upper } \\
\text { limit }\end{array}$ & & \\
\hline \multicolumn{8}{|l|}{ Prescription checks } \\
\hline Seldom & $16(88.9)$ & $2(11.1)$ & .0 & .000 & 17.9 & 1 & 0.008 \\
\hline Quite often & $9(56.3)$ & $7(43.8)$ & 1.1 & .073 & 110.1 & 1 & \\
\hline Very often & $3(27.3)$ & $8(72.7)$ & 1.4 & .019 & 2 & 1 & \\
\hline Always & $13(68.4)$ & $6(31.6)$ & & & & & \\
\hline $\begin{array}{c}\text { Calculation } \\
\text { medication } \\
\text { Quite often } \\
\text { Very often } \\
\text { Always }\end{array}$ & $\begin{array}{l}9(60) \\
9(69.2) \\
5(50) \\
18(69.2)\end{array}$ & $\begin{array}{l}6(40) \\
4(30.8) \\
5(50) \\
8(30.8)\end{array}$ & $\begin{array}{l}4.0 \\
1.0 \\
5.5\end{array}$ & $\begin{array}{l}.0 \\
.0 \\
.0\end{array}$ & 22.5 & $\begin{array}{l}1 \\
1 \\
1\end{array}$ & 0.701 \\
\hline $\begin{array}{l}\text { Preparation of infusion } \\
\text { medications. Seldom } \\
\text { Quite often }\end{array}$ & $\begin{array}{l}5(83.3) \\
4(44.4) \\
10(58.8)\end{array}$ & $\begin{array}{l}1(16.7) \\
5(55.6) \\
7(41.2)\end{array}$ & $\begin{array}{l}.0 \\
1.3 \\
2.0\end{array}$ & $\begin{array}{l}.0 \\
.1 \\
.3\end{array}$ & $\begin{array}{l}23.2 \\
15.3\end{array}$ & $\begin{array}{l}1 \\
1 \\
1\end{array}$ & 0.395 \\
\hline
\end{tabular}




\begin{tabular}{|c|c|c|c|c|c|c|c|}
\hline $\begin{array}{l}\text { Very often } \\
\text { Always }\end{array}$ & $22(68.8)$ & $10(31.3)$ & & & & & \\
\hline $\begin{array}{l}\text { Second registered nurse } \\
\text { checks Seldom } \\
\text { Quite often } \\
\text { Very often }\end{array}$ & $\begin{array}{l}18(66.7) \\
18(66.7) \\
5(50)\end{array}$ & $\begin{array}{l}9(33.3) \\
9(33.3) \\
5(50)\end{array}$ & $\begin{array}{l}.439 \\
.752\end{array}$ & $\begin{array}{l}.029 \\
.054\end{array}$ & $\begin{array}{l}6.6 \\
10.5\end{array}$ & $\begin{array}{l}1 \\
1\end{array}$ & 0.601 \\
\hline $\begin{array}{c}\text { Monitoring during } \\
\text { administration Seldom } \\
\text { Quite often } \\
\text { Very often } \\
\text { Always }\end{array}$ & $\begin{array}{l}2(40) \\
9(69.2) \\
15(55.6) \\
15(78.9)\end{array}$ & $\begin{array}{l}3(60) \\
4(30.8) \\
12(44.4) \\
4(21.1)\end{array}$ & $\begin{array}{l}456944 \\
679.2 \\
2.6 \\
1.872\end{array}$ & $\begin{array}{l}0.0 \\
0.4 \\
.1\end{array}$ & $\begin{array}{l}19.4 \\
26.2\end{array}$ & $\begin{array}{l}1 \\
1\end{array}$ & 0.252 \\
\hline
\end{tabular}

The study revealed that there was statistical significance between critical care nurses competence levels in the use of Microinfusion pumps and administration errors at a $\mathrm{P}<0.05$ with a chi square values of $(0.008)$ on prescription checks. Therefore, the researcher rejected the null hypothesis (H0) and accepted the alternative (H1) hence it's a source of Microinfusion medication administration errors as shown on table 3.

Those who were titrating the infusions and reported Microinfusion medication administration errors were more $56.1 \%(\mathrm{n}=23)$ unlike $43.9 \% \mathrm{n}=18)$ who were not titrating and reported Microinfusion medication administration errors.

Most of the respondents said that they are able to safely discontinue the infusion medication $79.7 \%(n=51)$ compared with $20.3 \%(n=13)$ who were not sure.

On post administration monitoring of patient, most of the respondents were monitoring $60.9 \%(\mathrm{n}=39)$ compared with $37.6 \%(n=34)$.

On safe disposal of administrative devices $89.1 \%(n=57)$ were always disposing the wastes while the rest $11 \%(\mathrm{n}=7)$ were not. On supervision, most of the respondents said that there were supervision and trainings at work place $73.4 \%(\mathrm{n}=47)$.

Reporting and documentation for Microinfusion medication administration errors was at $17.2 \%(\mathrm{n}=11)$, those who did not seem to know the guidelines and the process of reporting Microinfusion medication administration was $82.8 \%(\mathrm{n}=53)$, those respondents who were carrying identification checks was $87.6 \%$ $(n=56)$ those who did not $12.5 \%(n=8)$.

Majority of the respondents were carrying out prescription checks $90.7 \%(n=58)$ while $9.3 \%(n=6)$ did not. On checking of patient weight before drug administration those who estimated the patient weight were $84.4 \%(n=51)$ while those who confirmed $15.6 \%(n=13)$. Most of the respondents agreed that there was need for continuous monitoring and observation during administration of infusion medications $68.8 \%(n=47)$. Those who were not sure represented $31.3 \%(n=20)$.

The researcher found out that $56.2 \%(\mathrm{n}=36)$ respondents reported that it was necessary to have knowledge on the medication, the expected effects and how to manage the expected outcome before administering the drug.

A majority of the respondents $96.8 \% \quad(n=62)$ said that using the correct diluents can help reduce Microinfusion medication administration errors.

Proper labelling of medication infusions in accordance to local policy was one of the major ways the respondents reported $89 \%(\mathrm{n}=57)$ used to reduce medication administration errors. Those respondents who were able to identify Microinfusion medication administration errors early were the majority $82.8 \%(\mathrm{n}=53)$. 
A higher proportion of the respondents 59.4\% $(n=38)$ said that there is need for continuous treatment of anaphylaxis when a Microinfusion medication administration errors occur.

Table 4: Nurse Competency in the use of infusion pumps during administration of Microinfusion medication.

\begin{tabular}{|c|c|c|c|c|c|c|}
\hline \multirow[t]{2}{*}{ Characteristics } & \multirow{2}{*}{$\begin{array}{l}\begin{array}{l}\text { Overall } \\
(\mathrm{n}=64)\end{array} \\
\mathrm{n}(\%)\end{array}$} & \multicolumn{2}{|c|}{$\begin{array}{l}\text { Having made a } \\
\text { medication error in } \\
\text { the last } 6 \text { months }\end{array}$} & \multirow[t]{2}{*}{$\begin{array}{l}95 \% \text { C.I. } \\
\text { for } \\
\operatorname{EXP}(B)\end{array}$} & \multirow[t]{2}{*}{ Df } & \multirow[t]{2}{*}{$\begin{array}{c}\text { P- } \\
\text { Value }\end{array}$} \\
\hline & & Yes & No & & & \\
\hline $\begin{array}{l}\text { Monitoring post } \\
\text { administration } \\
\text { Seldom } \\
\text { Quite often } \\
\text { Very often } \\
\text { Always }\end{array}$ & $\begin{array}{l}4(6.3) \\
20(31.3) \\
26(40.6) \\
13(20.3)\end{array}$ & $\begin{array}{l}0 \\
12(60) \\
17(65.4) \\
11(84.6)\end{array}$ & $\begin{array}{l}4(100) \\
8(40) \\
9(34.6) \\
2(15.4)\end{array}$ & $\begin{array}{l}0.0(0.0) \\
5.5(0.0) \\
0.0(0.0) \\
1(0.0)\end{array}$ & $\begin{array}{l}1 \\
1 \\
1 \\
1\end{array}$ & 0.037 \\
\hline $\begin{array}{l}\text { Reporting and } \\
\text { documenting in case of an } \\
\text { error Never } \\
\text { Seldom } \\
\text { Quite often } \\
\text { Very often }\end{array}$ & $\begin{array}{l}30(46.9) \\
23(35.9) \\
10(15.6) \\
1(1.6)\end{array}$ & $\begin{array}{l}17(56.7) \\
20(87) \\
3(30) \\
1(100)\end{array}$ & $\begin{array}{l}13(43.3) \\
3(13) \\
7(70) \\
0\end{array}$ & $\begin{array}{l}39800.0(0 . \\
0) \\
0.2(0.0) \\
0.0(0)\end{array}$ & $\begin{array}{l}1 \\
1 \\
1 \\
1\end{array}$ & 0.009 \\
\hline $\begin{array}{l}\text { Weight check } \\
\text { Never } \\
\text { Seldom } \\
\text { Quite often }\end{array}$ & $\begin{array}{l}33(51.6) \\
21(32.8) \\
10(15.6)\end{array}$ & $\begin{array}{l}16(48.5) \\
18(85.7) \\
7(70)\end{array}$ & $\begin{array}{l}17(51.5) \\
3(14.3) \\
3(30)\end{array}$ & $\begin{array}{l}0.0 \\
0.0 \\
0.0\end{array}$ & $\begin{array}{l}1 \\
1 \\
1\end{array}$ & 0.019 \\
\hline $\begin{array}{l}\text { Use of correct diluents } \\
\text { Never } \\
\text { Seldom } \\
\text { Quite often } \\
\text { Very often } \\
\text { Always }\end{array}$ & $\begin{array}{l}1(1.6) \\
1(1.6) \\
15(23.4) \\
21(32.8) \\
26(40.6)\end{array}$ & $\begin{array}{l}0 \\
1(100) \\
9(60) \\
9(42.9) \\
22(84.6)\end{array}$ & $\begin{array}{l}1(100) \\
0 \\
6(40) \\
12(57.1) \\
4(15.4)\end{array}$ & $\begin{array}{l}1.0(0.0) \\
1.0(0.0)\end{array}$ & $\begin{array}{l}1 \\
1 \\
1 \\
1\end{array}$ & 0.023 \\
\hline
\end{tabular}




\begin{tabular}{|l|l|l|l|l|l|l|}
\hline Early identification & & & & & & \\
Never & $1(1.6)$ & 0 & $1(100)$ & 0.0 & 1 & \\
Seldom & $10(15.6)$ & $6(60)$ & $4(40)$ & 0.0 & 1 & 0.022 \\
Quite often & $14(21.9)$ & $10(71.4)$ & $4(28.6)$ & 0.0 & 1 & \\
Very often & $21(32.8)$ & $18(85.7)$ & $3(14.3)$ & 0.0 & 1 & \\
Always & $18(28.1)$ & $7(38.9)$ & $11(61.1)$ & 0.0 & & \\
\hline $\begin{array}{l}\text { Communication with } \\
\text { multidisciplinary team }\end{array}$ & $11(17.2)$ & $10(90.9)$ & $1(9.1)$ & $1.0(0.0)$ & 1 & \\
Never & $17(26.6)$ & $8(47.1)$ & $9(52.9)$ & $1.0(0.0$ & 1 & \\
Seldom & $22(34.4)$ & $20(90.9)$ & $2(9.1)$ & 0 & 1 & 0.000 \\
Quite often & $12(18.8)$ & $2(16.7)$ & $10(83.3)$ & 0.3 & 1 & \\
Very often & $2(3.1)$ & $1(50)$ & $1(50)$ & $>1$ & 1 & \\
Always & & & & & & \\
\hline
\end{tabular}

The study revealed that there was statistical significance between critical care nurses competence levels in the use of Microinfusion pumps and administration errors at a $\mathrm{P}<0.05$ with significant chi square values of $(0.009,0.019,0.023,0.022,0.000)$ on reporting and documenting in case of an error, weight check, use of correct diluents, early identification, communication with a multi disciplinary team. Therefore, the researcher rejected the null hypothesis (H0) and accepted the alternative (H1) hence this amounts to a source of Microinfusion medication administration errors as shown on table 4.

\section{Discussion}

\subsection{Demographic Characteristics of the Respondents and micro infusion medication administration errors}

The higher incidence of Microinfusion medication administration errors were more among male nurses. This is an indication that Microinfusion medication administration errors are expressed differently between sexes though the margin was narrow. No any other publication has ever shown such a relationship. A number of studies(Wallace, 1996; Patel and Balk, 2007; World Health Organisation (WHO), 2008; Neil, 2017; Schutijser et al., 2018) had found strong associations between age of respondents and Microinfusion medication administration errors as due to memory lapses but this study did not align to this findings. Any advance in age indicates decreased incidence of Microinfusion medication administration errors. This could have been attributed to experience that the respondent gain at work place, making them to be more careful when discharging their duties.

\subsection{Critical care nurses competency and micro infusion medication administration errors}

The department had the most experienced nurses at the time of the study with most of them having experience of more than ten years. The level of education had no direct relationship with Microinfusion medication administration errors since majority of the respondents had a higher diploma and degree in nursing but still more than sixty percent reported Microinfusion medication administration errors during their practice. Those nurses who were new in the department or newly employed with little experience higher chances of having Microinfusion medication administration errors and this result were same as those released in a study by(Morrison et al., 1994) that indicated that new nurses with low level experience were at increased chances of having Microinfusion medication administration errors while administering medications. 
This study showed the need for monitor patients after drug administration always so as to be able to identify any a deviations in dynamics and to also note the errors and therefore initiate immediate medical response to prevent further injuries to patients. These results are consistent with studies published by(College and Association of Registered Nurses of Alberta, 2014)

A number of studies by (Medical Product Agency, 2014) and (Edwards and Axe, 2015) have found strong associations between reporting and documenting care provided timely and Microinfusion medication administration errors whenever they occur. This was also evident from in this study with those respondents who reported fewer incidences of errors being the ones who were always reporting and documenting errors and carrying out reviews to prevent future occurrences. This can reduce cost of hospitalization and reduce morbidity and mortality in critical care patients (Ebrahimipour et al., 2014)

Previous studies by (Moyen, Camiré and Stelfox, 2008) and (Katzung and Trevor, 2015) have emphasized need to take weight of patients always check patient weight for drug calculations and for monitoring critical care patients progress. This has been consistently replicated in this current study as it had a strong association with Microinfusion medication administration errors. Those respondents who were not keen at taking weight of patients had difficulties getting drug dosages and reported more medication errors. This study showed that it was important to have all beds be able to take weight of patients to reduce errors.

This study also investigated the relationship between using the right diluents, having mechanisms for reporting Micsroinfusion medication administration errors and the need for early identification. Results indicated that these factors could predict the likelihood of having MAEs and thus can help in reducing then and even preventing them.

\section{Acknowledgement}

I take this opportunity to appreciate my Lecturers of the department of Critical care for their mentorship and guidance, I am especially grateful to my supervisors Ms. Hannah Inyama and Mrs. Eve Rajula of the University of Nairobi, School of Nursing Sciences for their continuous guidance and support throughout the research period.

I would like to thank Mr. Jared Osoro- statistician, Dr.Omonge Lecturer University of Nairobi Department of clinical pharmacology and Dr. Lydiah Okutoyi Head of patient safety, Kenyatta National Hospital who remained so committed in guiding me from time to time.

I would not forget to thank all the respondents for volunteering to participate in the study, together with Kenyatta National Hospital and University of Nairobi Ethics and Research committee for giving me permission to conduct my study.

I extend my sincere gratitude and appreciation to my colleagues, MScN class of 2018, the entire CCU staff, the Nurses, Doctors and every staff working in the critical care units within Kenyatta National Hospital who were supportive and kind to me during my study and research period.

Last but not least I appreciate the opportunity granted me by The University of Nairobi and Kajiado County Government to advance my studies.

\section{References}

[1.] Abdel-Latif, M. M. (2016) 'Knowledge of healthcare professionals about medication errors in hospitals', Journal of Basic and Clinical Pharmacy, 7(3), p. 87. doi: 10.4103/0976-0105.183264.

[2.] Al-shara, M. (2011) 'Factors contributing to medication errors in Jordan: a nursing perspective', 16(2), pp. 158-161.

[3.] Aljadhey, H., Mahmoud, M. A., Ahmed, Y., Sultana, R., Zouein, S., Alshanawani, S., Mayet, A., Alshaikh, M. K., Kalagi, N., Al Tawil, E., El Kinge, A. R., Arwadi, A., Alyahya, M., Murray, M. D. and Bates, D. (2016) 'Incidence of adverse drug events in public and private hospitals in Riyadh, Saudi Arabia: the (ADESA) prospective cohort study', BMJ open, 6(7), p. e010831. doi: 10.1136/bmjopen-2015-010831.

[4.] Alsulami, Z. N., Aldosseri, A. F., Ezziden, A. S. and Alonazi, A. K. (2015) 'Evaluation of Medication Administration Process in a Paediatric Ward', International Journal of Medical, Health, Biomedical, Bioengineering and Pharmaceutical Engineering, 9(1), pp. 5-8. 
[5.] Bassi, E., Park, M. and Azevedo, L. C. P. (2013) 'Therapeutic strategies for high-dose vasopressordependent shock', Critical Care Research and Practice, 2013. doi: 10.1155/2013/654708.

[6.] College and Association of Registered Nurses of Alberta (2014) 'Medication guidelines', (March), pp. $1-49$.

[7.] Cour, M., Hernu, R., Bénet, T., Robert, J. M., Regad, D., Chabert, B., Malatray, A., Conrozier, S., Serra, P., Lassaigne, M., Vanhems, P. and Argaud, L. (2013) 'Benefits of smart pumps for automated changeovers of vasoactive drug infusion pumps: A quasi-experimental study', British Journal of Anaesthesia. The Author(s), 111(5), pp. 818-824. doi: 10.1093/bja/aet199.

[8.] Ebrahimipour, H., Hosseini, S. E., Haghighi, H. and Tabatabaee, S. S. (2014) 'Evaluation of Medication Errors by Nurses in Hospitals Affiliated with Mashhad University of Medical Sciences , Mashhad, Iran', Patient Safety \& Quality Improvement Journal, 1(10), pp. 400-404.

[9.] Edwards, S. and Axe, S. (2015) 'The ten "R" $s$ of safe multidisciplinary drug administration', Nurse Prescribing, 13(8), pp. 352-360. Available at: http://collections.crest.ac.uk/9407/1/Edwards\%2C Sharon Axe\%2C Sue 10 'R's of safe multidisciplinary drug administration.pdf.

[10.] Erdman, M. J., Riha, H., Bode, L., Chang, J. J. and Jones, G. M. (2017) 'Predictors of Acute Kidney Injury in Neurocritical Care Patients Receiving Continuous Hypertonic Saline', The Neurohospitalist, 7(1), pp. 9-14. doi: 10.1177/1941874416665744.

[11.] Faye, H., Rivera-Rodriguez, A. J., Karsh, B.-T., Hundt, A. S., Baker, C. and Carayon, P. (2010) 'Involving intensive care unit nurses in a proactive risk assessment of the medication management process', Joint Commission journal on quality and patient safety, 36(8), p. 376-384. doi: 10.1016/s1553-7250(10)36056-9.

[12.] Girardis, M., Rinaldi, L., Donno, L., Marietta, M., Codeluppi, M., Marchegiano, P. and Venturelli, C. (2009) 'Effects on management and outcome of severe sepsis and septic shock patients admitted to the intensive care unit after implementation of a sepsis program: A pilot study', Critical Care, 13(5), pp. 1-8. doi: 10.1186/cc8029.

[13.] Gupta, B., Garg, N. and Ramachandran, R. (2017) 'Vasopressors: Do they have any role in hemorrhagic shock?', Journal of Anaesthesiology Clinical Pharmacology, 33(1), p. 3. doi: 10.4103/0970-9185.202185.

[14.] Joint commission international accreditation (2011) joint commission international accreditation standards for hospitals. Edited by 4TH. illinois,USA: joint commission international. Available at: http://www.jointcommissioninternational.org.

[15.] Karavasiliadou, S. and Athanasakis, E. (2014) 'An inside look into the factors contributing to medication errors in the clinical nursing practice', Health Science Journal, 8(1), pp. 32-44.

[16.] Katzung, B. G. and Trevor, A. J. (2015) 'Basic and Clinical pharmacology', in Katzung, B. G. and Trevor, A. J. (eds). McGraw-Hill Education,Lange medical publications,Appleton and Lange, p. 1216.

[17.] Li, Q., Chen, H., Hao, J. J., Yin, N. N., Xu, M. and Zhou, J. X. (2015) 'Agreement of measured and calculated serum osmolality during the infusion of mannitol or hypertonic saline in patients after craniotomy: A prospective, double-blinded, randomised controlled trial', $B M C$ Anesthesiology. BMC Anesthesiology, 15(1), pp. 1-10. doi: 10.1186/s12871-015-0119-4.

[18.] Machado, D. A., Figueiredo, N. M. A. de, Velasques, L. de S., Bento, C. A. de M., Machado, W. C. A. and Vianna, L. A. M. (2018) 'Cognitive changes in nurses working in intensive care units', Revista Brasileira de Enfermagem, 71(1), pp. 73-79. doi: 10.1590/0034-7167-2016-0513.

[19.] McDowell, S. E., Ferner, H. S. and Ferner, R. E. (2009) 'The pathophysiology of medication errors: how and where they arise', British journal of clinical pharmacology, 67(6), p. 605-613. doi: 10.1111/j.1365-2125.2009.03416.x.

[20.] Medical Product Agency (2014) 'Infusion pumps - Identifying risks Report from the Medical Products Agency', 46(August). 
[21.] Morrison, P. F., Laske, D. W., Bobo, H., Oldfield, E. H. and Dedrick, R. L. (1994) 'High-flow microinfusion: tissue penetration and pharmacodynamics.', The American journal of physiology, 266(1 Pt 2), pp. R292-R305.

[22.] Moyen, E., Camiré, E. and Stelfox, H. T. (2008) 'Clinical review : Medication errors in critical care', 7(Table 1), pp. 1-7. doi: 10.1186/cc6813.

[23.] Neil, R. (2017) 'Infusion Pump-Makers Look to Improve Safety Through Interoperability', (2016).

[24.] Patel, G. P. and Balk, R. A. (2007) 'Choice of vasopressor in septic shock: Does it matter?', Critical Care, 11(6), pp. 11-12. doi: 10.1186/cc6159.

[25.] Programs, O. H. (no date) 'THE HEALTH CARE INDUSTRY AND'.

[26.] Sada, O., Melkie, A. and Shibeshi, W. (2015) 'Medication prescribing errors in the medical intensive care unit of Tikur Anbessa Specialized Hospital, Addis Ababa, Ethiopia', BMC research notes, 8, p. 448. doi: 10.1186/s13104-015-1435-y.

[27.] Schutijser, B., Klopotowska, J. E., Jongerden, I., Spreeuwenberg, P., Wagner, C. and De Bruijne, M. (2018) 'Nurse compliance with a protocol for safe injectable medication administration: Comparison of two multicentre observational studies', BMJ Open, 8(1), pp. 1-10. doi: 10.1136/bmjopen-2017-019648.

[28.] This, D. (2018) 'Evaluation and modelling of dosing errors in multi-infusion Evaluation and modelling of dosing errors in multi-infusion Master thesis by ':

[29.] U.S. Food and Drug Administration (2010) 'Infusion Pump Improvement Initiative', (April). Available http://www.fda.gov/MedicalDevices/ProductsandMedicalProcedures/GeneralHospitalDevicesandS upplies/InfusionPumps/ucm205424.htm.

[30.] Wallace, P. G. (1996) 'Infusion systems.', Anaesthesia, 51(7), pp. 613-614. doi: 10.1111/j.13652044.1996.tb07840.x.

[31.] Whalen, K., Finkel, R. and Panavelil, T. A. (2015) Lippincott Illastrated Reviews: Pharmacology. 6th edn. Kluwer Health,Lippincott Williams \& Wilkins.

[32.] WHO (2017) Medication Errors, Nursing. doi: 10.1097/01.NURSE.0000524761.58624.1f.

[33.] World Health Organisation (WHO) (2008) 'Patient Safety Workshop: Learning from error', Rebuilding Trust in Healthcare, pp. 121-130. doi: 10.1007/978-3-319-00041-1.

[34.] World Health Organisation (WHO) (2012) 'Frequently asked questions ( FAQ' s ): Infusion Pump', pp. 1-2.

[35.] World Health Organization (2014) 'Reporting and Learning System for Medication Errors: The Role of Pharmacovigilance Centres', WHO Press, p. 96. Available at: http://apps.who.int/iris/bitstream/10665/137036/1/9789241507943_eng.pdf?ua=1\%0Ahttp://apps. who.int/iris/bitstream/10665/137036/1/9789241507943_eng.pdf. 